\title{
The Application Of Kohlberg's Moral Development Model To College Students' Technology Ethics Decisions
}

Angelina I. T. Kiser, University of the Incarnate Word, USA

Eileen E. Morrison, Texas State University-San Marcos, USA Annette Craven, University of the Incarnate Word, USA

\begin{abstract}
This study examined undergraduate university students' ( $n=121)$ responses to six ethical dilemmas within the realm of information technology (IT). Using a framework based on Kohlberg's stages of moral development, the study evaluated the level of moral development as demonstrated in these responses. An apriori coding system was used to analyze the data. Two researchers independently assigned coding to the written responses in order to increase interrater reliability. The results are presented by student classification (freshman, sophomore, junior, or senior) and each individual scenario. They indicate a strong tendency for students to use the "good person" form of reasoning. This reasoning, however, did vary by scenario.
\end{abstract}

Keywords: Ethics, Kohlberg, technology, moral development, reasoning, college students

\section{INTRODUCTION}

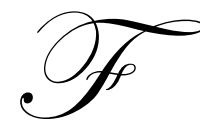

or many students, college is the first time that they are faced with values and perspectives that conflict with those that their families instilled (Schrader 1999). They are faced with situations where there is no clear answer and where a system of ethical reasoning is paramount. While ethics challenges may be found in all areas of student life, the pervasive use of technology creates new areas of concern.

Today's students are far more comfortable with technology than their predecessors. Text messaging, laptops, and social networks are accepted as part of life. With this technology comes the potential for ethics challenges such as property theft, identity theft, loss of privacy, and hacking. Such issues can cause both mental and financial harm to those affected. For example, if someone illegally downloads music, the person who recorded the music is financially affected. Additionally, the person who downloaded the music could face legal action leading to fines or jail. Technology-based challenges require students' ability to apply ethics-based reasoning to their decisions for both personal and professional actions. Therefore, it is important for educators to assess the current level of moral reasoning among students who are part of the current age of technology. There is also a responsibility to provide opportunities to increase moral reasoning with respect to technology.

This study is significant because it expands Kohlberg's model to the area of information technology. Using his stages, the authors created a scale to determine the level of moral reasoning among students responding to technology-based scenarios. The results of this and further studies can offer suggestions for improving curriculum to address the ethics component of information technology in higher education. The information is valuable to higher education professors and researchers because it provides important insight into college students' decision-making processes. That insight can then provide a basis for teaching ethical values and increasing ethical decision making for those same students who will eventually enter the workforce and become the leaders of tomorrow. Furthermore, researchers can use this same type of model to perform studies in areas other than information technology. 


\section{REVIEW OF THE LITERATURE}

"The combination of a rapid pace in IT changes along with accelerated distribution networks creates momentum for technology advancement outpacing ethical development in a society" (Woodward, Davis, and Hodis 2007 p. 197). The possibility for information technology abuse continues to be a concern for companies and individuals alike. While individual societies create their own ethical systems, the technology of computer networks abandons the idea of the "local" point of reference, and a state of global information technology ethics emerges (Gorniak-Kocikowska 2006). In response to the overwhelming concern over ethics, more than $90 \%$ of corporations have made ethics and ethical behavior one of their top priorities (Murphy 2003). Additionally, companies are requiring employee training in both ethical reasoning and ethical behavior (Velthouse and Kandogan 2007).

The purpose of this study was to use information technology-type scenarios to examine the level of moral development among undergraduate students. Kohlberg originally developed his stage theory when he analyzed the responses of 72 upper-middle to lower-middle class boys ages 10,13, and 16 to hypothetical moral dilemmas (Austrian 2002). He later used the same format to analyze the responses of 16-year-old delinquent boys and 50 13year-old boys and girls in order to determine the children's reasoning that led to their answers and not the answers themselves (Austrian 2002).

Kohlberg's research led him to develop six stages of moral development, and he claimed that each new stage was psychologically better than the previous stage (Lapsley 1996). The scoring method itself went through several changes before the final development of the Structural Issue and Standard Issue Scoring system that achieved greater objectivity and reliability (Lapsley 1996). Because of this scoring system, Stage 6 was dropped and was simply considered a hypothetical endpoint (Lapsley 1996). Scoring manuals do not even contain directions for scoring Stage 6, and Kohlberg felt that intercoder reliability was improved by omitting it as a scoring possibility (Rest 1994).

The 5 Stages of Moral Development as defined by Kohlberg (1981) are:

Stage 1: The Stage of Punishment and Obedience. Do what you are told in order to avoid punishment.

Stage 2: The Stage of Individual Instrumental Purpose and Exchange. The reason for doing what is right is to serve one's self-interests.

Stage 3: The Stage of Mutual Interpersonal Expectations, Relationships, and Conformity. If one is considerate, nice, and kind, one will be seen as a "good person."

Stage 4: The Stage of Social System and Conscience. The emphasis is on obeying laws and respecting authority.

Stage 5: The Stage of Prior Rights and Social Contract or Utility. People freely enter into societal contracts and are obligated by the arrangements they agreed to by due process procedures.

Each stage is categorized into one of three levels: 1. Preconventional (Stages 1 and 2), 2. Conventional (Stages 3 and 4), and 3. Postconventional (Stage 5 and hypothetical Stage 6). In the preconventioal level, moral rules and norms are imposed on people from external authorities. People whose responses fall within the conventional level internalize the expectations of authority. And lastly, at the postconventional level, moral options are best defined by self-chosen principles (Lapsley 1996).

Kohlberg's theory on moral development postulates that ethical reasoning is not static, but rather a person is able to move up from one stage to the next. Therefore, we each have the ability to move to Kohlberg's Stage 5 when faced with moral dilemmas. Any student who uses technology can be faced with a technology-related moral dilemma, and it is important to understand ethical training and assessment of information technology students in order for ethical development to take place (Woodward, Davis, and Hodis 2007). As Kohlberg (1981, p. 2) stated, “... like it or not teachers are moral educators (or miseducators) as creators of the "hidden curriculum" of the moral climate of the classroom" 


\section{METHODOLOGY}

Information systems research, although traditionally limited to technology, has been expanded to include behavioral and organizational considerations (Galliers and Land 2002). The focus of this study was on the moral development of college students. This moral development ultimately affects behavior and thus must be a consideration for universities and organizations. Understanding how college students use reason to assess and make decisions about ethical dilemmas in technology gives the college professor insight and an opportunity to advance the students' moral reasoning so that there is a greater chance that those students will make ethical decisions in the future.

This descriptive qualitative study used a survey instrument designed to evaluate students' level of reasoning according to Lawrence Kohlberg's stages of moral development. The survey included six scenarios that gave examples of ethical dilemmas in information technology that a student might encounter. For example, one scenario dealt with sharing usernames and passwords. Students were asked to state whether the action taken in each scenario was ethical or not and to explain their answers. The survey and its implementation required no identifying information; therefore, all respondents were completely anonymous. After receiving approval from the Institutional Review Board, the researchers identified faculty members who were willing to assist with the research by informing their students about the survey.

The survey was posted online using www.SurveyMonkey.com so that students could complete it at their convenience. Each professor followed the same procedure and offered no extra credit for participation in the study. The reasons for the research and instructions for the completing the survey were given to each student. Participants were asked to provide yes/no responses to each scenario question and then open-ended responses to the why/why not portion of the questions. The survey was available for four weeks in order to allow ample time to collect the data.

The purpose of the survey was not to judge whether the students answered ethically to the scenarios provided on the survey, but rather to ascertain their levels of moral reasoning. Using Kohlberg's stages, apriori codes were developed for analysis of moral reason. This step was important because qualitative researchers working in teams should agree from the beginning on the meanings of the codes they will use in the coding process (Ryan and Bernard 2003). To increase the validity and reliability of data, multiple coders typically code the text in order to verify that the constructs being investigated are shared and that the coders can reliably apply the proper codes to the text (Ryan and Bernard 2003). Therefore, the researchers agreed in advance that the following criteria would be used to determine into which level of reasoning the students' responses fell.

For the purpose of this study, Levels 1-5 were used for coding the student responses, and these levels corresponded to Kohlberg's Stages 1-5 listed previously.

1) Level 1 - being obedient in order to avoid punishment;

2) Level 2 - concerned with own self interests;

3) Level 3 - being seen as a good person;

4) Level 4 - respect for law and authority; and

5) Level 5 - doing something simply because it is the right thing to do.

Once data collection was completed, the researchers used their apriori coding system to evaluate each individual student response. Qualitative research often calls for researchers to identify themes within responses or text (Ryan and Bernard 2003). In this study the researches sought out common words or phrases within the body of the responses to determine into which level each response fell. To ensure interrater reliability, the two researches conducted their coding of the student responses individually and assigned a 1, 2, 3, 4 or 5 to each scenario for each student. Then the researchers met to check for consistency. If any responses were not coded the same the researchers discussed the issue and came to a consensus. Both researchers agreed upon all final coding.

To illustrate how the coding was established, the following responses are examples of the varying coding schemes. Level 1 responses, which were coded according to the response indicating some sort of punishment, 
included such comments as, "Because that can come back to haunt you." and "There could be serious consequences." One of the most common comments for Level 1 coding also included statement from the respondents about getting into "trouble".

Level 2 responses, which indicated a concern for oneself, included such comments as, "We shouldn't pay more than we have to." and "School is expensive." These types of answers indicated to the researchers that the respondents were concerned with themselves as opposed to being concerned about the welfare of others. The responses in level 2 did not indicate any anxiety about being obedient or being punished for a particular action.

Level 3 responses, which are considered a higher stage of moral reasoning than levels 1 and 2, signified that the respondents wanted to be viewed as being a good person or doing the right thing. Responses that fell into this category included such statements as, "It is the right thing to do." and "It is their responsibility." If a participant responded with "It's ethical.", but made no comment about the consequences to others, the response was coded a level 3.

Responses that pointed toward a greater concern for authority or law were coded as level 4 . These replies included statements such as, "It is an invasion of privacy." and "That would be stealing." Unlike level 3, the students went beyond just being a good person and moved toward looking at authority or law within the greater society. There was a concern for the effect of an action on other people.

Level 5 responses went further than level 4 responses because the respondents now considered doing something because of their consciences. The threat of punishment or the fact that something was law was not the motivating factor. These responses included such statements as, "Someone shouldn't hurt other people/things in the name of research." and "Everyone has the right to their own personal information."

\section{PARTICIPANTS}

The invited participants in this study were 179 undergraduate students at the University of the Incarnate Word in San Antonio, Texas during the spring, 2008 semester. All students were enrolled in either Computer Literacy $(n=131)$ or Introduction to Information Systems $(n=48)$. A total of 138 participants started the online survey instrument, and 132 answered "yes" to agreeing to participate, 2 answered "no" to agreeing to participate, and 4 skipped the question about agreeing to participate but completed the survey. The responses of the four students who did not answer the question about agreeing to participate were removed from the final sample. Of the 132 who responded and agreed to allow their survey responses to be used for research purposes, 11 were omitted from the final study due to a lack of sufficient information in their responses. Table 1 presents the response rates for this study.

Table 1

Response Rates $(n=121)$

Invited Undergraduate Participants
- 131 Computer Literacy Students
- 48 Information System Students
179

Undergraduate Respondents

Computer Literacy is a liberal arts core curriculum requirement for all UIW students and Information Systems is a core business requirement for all business majors. The responses of the final 121 students who provided valid responses and agreed to allow their answers to be used for research purposes were included in the research, and the final sample consisted of 59 freshmen, 25 sophomores, 22 juniors, and 15 seniors. 


\section{FINDINGS}

Upon completion of the coding process, the data were profiled by question and classification (freshman, sophomore, junior, and senior) to assess trends. The final sample was comprised of $48.8 \%$ freshmen, $20.7 \%$ sophomores, $18.2 \%$ juniors, and $12.4 \%$ seniors. The researchers expected the sample to be a majority of freshmen since students typically complete the computer literacy course in their first year at the university. Table 2 presents the combined coding $(1-5)$ results for all six scenarios according to the student classification.

Table 2

Coding Results by Student Classification ( $n=121)$

\begin{tabular}{lccccc}
\hline Classification & \multicolumn{5}{c}{ Response Levels (\%) } \\
\hline Freshmen & Level 1 & Level 2 & Level 3 & Level 4 & Level 5 \\
Sophomore & 7.21 & 22.82 & 29.13 & 25.53 & 15.32 \\
Junior & 7.02 & 26.32 & 38.60 & 13.16 & 14.91 \\
Senior & 5.50 & 25.69 & 28.44 & 19.27 & 21.10 \\
\hline
\end{tabular}

The results indicated that all student classifications had the highest percentage of Level 3 responses, which indicated the importance of being seen as a good person. The distribution for level 3 responses was freshman, $29.13 \%$, sophomores, $38.6 \%$, juniors, $28.44 \%$, and seniors, $31.17 \%$. Additionally, juniors had the greatest frequency $(21.10 \%)$ of level 5 responses, while seniors had the lowest frequency (9.09\%) of level 5 responses. Although it might be expected that seniors have the highest level of moral development that was not the case in this study. In fact, seniors also had a higher frequency (11.69\%) of level 1 responses than freshmen, sophomores, or juniors. Level 1 indicated that the students' reasons for taking a particular action were to avoid punishment. This level of moral development is the lowest in Kohlberg's stages.

For level 4 responses, freshmen had the highest percentage of frequency at $25.53 \%$, while the other student classifications for level 4 responses fell between $13.16 \%$ and 19.27\%. Combining the level 4 and level 5 codes, freshmen and sophomores had a percentage frequency of $40.85 \%$ and $40.37 \%$ respectively. On the other hand, sophomores and seniors had a significantly lower percentage frequency of the combined level 4 and level 5 codes with $28.07 \%$ and $27.27 \%$ respectively.

The data were also analyzed according to the scenarios. Table 3 illustrates the total percentage of each level $(1-5)$ for each individual scenario.

Table 3

Coding Results by Scenario $(n=121)$

\begin{tabular}{lcrrrr}
\hline Scenario (\#) & \multicolumn{5}{c}{ Response Levels (\%) } \\
\hline & Level 1 & Level 2 & Level 3 & Level 4 & Level 5 \\
\hline 1 & 1.72 & 6.03 & 30.72 & 33.62 & 14.66 \\
3 & 18.10 & 28.57 & 29.52 & 12.38 & 11.43 \\
4 & 4.76 & 19.05 & 17.14 & 3.81 & 55.24 \\
5 & 16.50 & 28.16 & 23.30 & 26.21 & 5.83 \\
6 & 1.98 & 46.53 & 6.93 & 44.55 & 0.00 \\
\hline
\end{tabular}

Scenario \#1: A student gains access to other students' academic records. Should he/she continue to view the grades until the problem is fixed even if he/she does not share the information with anyone?

For this particular scenario, the vast majority of responses fell into the level 3 or level 4 categories with $30.72 \%$ and $33.62 \%$ respectively. Therefore, students felt that this situation was not necessary about getting into 
trouble, but rather about being seen as someone who does what is considered to be the right thing to do and being concerned about the privacy of others. Only $1.72 \%$ of the respondents felt that getting into trouble was an issue for this scenario, and only $6.03 \%$ felt that there was something in it for them.

Scenario \#2: A student discovers that the university has erroneously credited his/her account for one full semester of tuition costs. Should he/she inform anyone?

This scenario actually presented a case in which the students would financially benefit if the error were not discovered. Only $24.81 \%$ of the responses fell into the level 4 or level 5 categories. While $29.52 \%$ of the responses did indicate a concern for being seen as a good person, an almost equal amount of responses, $28.57 \%$, specified a greater concern for self. More students were concerned with punishment with this scenario than in any of the other scenarios.

Scenario \#3: A student is doing research on computer viruses and develops a harmless virus that only prints "Hello!" on a person's computer screen. Should he/she send out the virus to help with the research?

Scenario \#3 had by far the greatest number of responses that were coded as level 5 . The level 5 coding for this scenario was $55.24 \%$. The next closest level 5 responses came in scenario \#1 with $14.66 \%$. Only $4.76 \%$ of the responses indicated a fear of punishment. The researchers concluded that this scenario is probably one that has affected more students than any other scenario. Having had personal experiences and problems with computer viruses may have made the students more empathetic towards others.

Scenario \#4: Should a student share his/her university username and password with a friend so that he/she can use the university's online library?

Level 2 accounted for the greatest percentage of responses for this category with $28.16 \%$. However, level 3 responses were at $23.30 \%$, and level 4 responses were at $26.21 \%$. One of the concerns that was discovered in the responses was that students were afraid that if they allowed someone else to use their university username and password, that other person might do something that would ultimately get the responding student into trouble. This is probably the reason that $16.50 \%$ of the responses were coded as level 1 .

Scenario \#5: As a college student, software was loaded on a student's laptop that was designated for educational purposes only, and he/she was instructed to remove the software once he/she graduated. Should he/she continue to use the software after graduation?

None of the responses for this scenario was coded as level 5. Some students felt that they had a right to use the software even after graduating, which probably explains why $46.53 \%$ of the responses fell into level 2 . On the other hand, those who felt that students should not continue to use the software felt so because of the rules or authority of the university, which explains why $44.55 \%$ of the responses fell into level 4 . A mere $6.93 \%$ of responses fell into level 3, while even fewer students were concerned about any type of negative repercussions as only $1.98 \%$ of responses were coded as level 1.

Scenario \#6: Should a student pretend to be a cancer patient in an online chat room in order to gather information for a paper he/she is writing for one of his/her classes?

An immense majority of the responses were coded as level 3 with $63.11 \%$ of them indicating a concern with being a good person. However, the second highest percentage of responses was level 2 with $23.30 \%$. Only a combined total of $11.65 \%$ of the responses were coded as either level 4 or level 5 . Therefore, a high concern for society was not present for this scenario. In addition, only $1.94 \%$ of the responses indicated a fear of punishment, and were coded as level 1. 


\section{DISCUSSION, CONCLUSIONS \& RECOMMENDATIONS}

Information technology has brought forth a new realm of ethical issues. Online access to all sorts of information has created situations that, while not illegal, test capacity for moral and ethical reasoning. This study sought to determine students' level, or stage, of moral reasoning according to the framework developed by Lawrence Kohlberg. The researchers provided six scenarios that involved a variety of technology dilemmas that would be relevant to university students. This procedure was implemented so that the students would have a sense of the situations and be able to answer from a perspective that they felt was significant.

The greatest percentage of students' responses fell into the level 3 coding category, which indicated the intention to be seen as a good person. Nidich, Nidich, and Alexander (2000) posit that a very small percentage of the adult population actually reaches Kohlberg's stage 5 of moral development, and the predominance lies within stages 3 and 4. Stages 1 and 2 are typically present prior to the development of the "intellect", while the remaining stages are present after the development of the "intellect" (Nidich, Nidich, and Alexander 2000). For the undergraduate students in this study, level 2 coding had the second highest percentage of responses. This can be expected when considering the development of the "intellect" since the greatest number of students were freshmen and just beginning their academic career.

The research was limited to undergraduate students currently taking a computer literacy or information systems classes. However, because the computer literacy class is required for all students at the university, the students fall into a wide range of college majors. There are opportunities to expand the research to include a greater number of students, especially sophomores, juniors, and seniors. A longitudinal study could be conducted to determine if students develop a higher level of moral reasoning over time at a college or university. Further research might include a breakdown of students by college major to determine if students majoring in a technology field have different moral reasoning levels when it comes to information technology than students in other disciplines. Further research might also include graduate students. These graduate students could offer a different perspective since they would have more professional work and life experiences.

To add more information to a study such as this, a qualitative approach could be used to enrich the results. Focus groups with students might provide some more in-depth information that could be used to validate the results achieved in this study through triangulation methodology. With these focus groups, the researchers could continue to investigate why students make the decisions they make.

It is important to understand the moral and ethical reasoning behind a person's decisions and not simply to know that they would make a particular decision. In a university setting, professors can use this type of information to help students understand the importance of making ethical decisions on a higher level. The results of this study specifically indicated that fear of punishment was not a major concern for the participants; it also indicated that students were concerned about being seen as good people. To get beyond this point, and to move further along Kohlberg's stages of moral development, it is imperative that students be taught how their decisions affect those around them and society as a whole. The students should also understand the importance of making ethical decisions regardless of whether or not anyone is affected. For example, if students reach Kohlberg's level 5 reasoning, they would refrain from such things as accessing confidential information when they are not authorized or illegally using software simply because it is the right thing to do. There is no fear of punishment and no one will see them as good people because no one is around. They make the decision to stop because that is the proper decision to make. While this level of moral reasoning is difficult to achieve, it should be our goal.

\section{AUTHOR INFORMATION}

Dr. Angelina Kiser is currently an Assistant Professor and Management Coordinator in the School of Business and Administration at the University of the Incarnate Word in San Antonio, TX. She earned her Ph.D. in Adult and Professional Education from Texas State University - San Marcos. Dr. Kiser teaches management and organizational behavior courses and continues to conduct research in the areas of ethics and cultural diversity. She has traveled throughout Europe, Mexico, and Guatemala to study the various cultural norms and traditions within those countries and received an Outstanding Research Award for her study in Guatemala. 
Eileen E. Morrison is a Professor and Director of the Bachelor's Degree Program in the School of Health Administration at Texas State University San Marcos. She has a doctorate from Vanderbilt University and a Master of Public Health degree from the University of Tennessee. Dr. Morrison teaches graduate and undergraduate ethics and provides ethics workshops to physicians, nurses, clinical laboratory and dental professionals, and counselors. She is the author of Ethics in Health Administration: A Practical Approach for Decision Makers and editor of Health Care Ethics: Critical Issues in the $21^{\text {st }}$ Century.

Annette E. Craven, Ph.D. is an Associate Professor of Management at University of the Incarnate Word in San Antonio, TX, and teaches Business Research, Human Resource Management, and Cross-Cultural Business Communication. She earned her Ph.D. in Higher Education Administration and Human Communications at the University of Denver, a Master of Human Relations and a Master of Education at the University of Oklahoma. She is an Illinois licensed CPA, served as a Malcolm Baldrige National Quality Program Examiner (2007-2009), has served on the Quality Texas (Baldrige) Award for Performance Excellence Board of Examiners and is currently a member of the ACBSP Baccalaureate Board of Commissioners.

\section{REFERENCES}

1. S. G. Austrian. Developmental Theories through the Life Cycle. Columbia University Press, 2002.

2. R. D. Galliers and F. F. Land. Choosing Appropriate Information Systems Research Methodologies. In M. D. Myers and D. Avison, editors, Qualitative Research in Information Systems, pp. 13-17, Sage Publications, London, England, 2002.

3. K. Gorniak-Kocikowska. From Computer Ethics to the Ethics of Global ICT Society. Library Hi Tech, 25(1): 47-57, 2007.

4. $\quad$ L. Kohlberg. Volume 1: The Philosophy of Moral Development, Harper \& Row, New York, 1981.

5. $\quad$ D. K. Lapsley. Moral Psychology. Westview Press, Boulder, CO, 1996.

6. P. E. Murphy. Trend in Ethics Codes: Address in Both Compliance and Values. Paper presented at The Southern Institute 2003 Seminar, Building a Better Code of Ethics, Summer 2003, Atlanta, GA.

7. J. R. Rest. Background: Theory and Research. In J. R. Rest and D. Navaez, editors, Moral Development in the Professions: Psychology and Applied Ethics, pp. 1-26, Lawrence Erlbaum Associates, Hillsdale, NJ, 1994.

8. G. W. Ryan and H. R. Bernard. Data Management and Analysis Methods. In N. K. Denzin and Y. S. Lincoln, editors, Collecting and Interpreting Qualitative Materials, pp. 259-309, Sage Publications, Thousand Oaks, CA, 2003.

9. D. E. Schrader. Metacognitive Reflection in University Students. In R. L. Mosher, D.J. Youngman, and J. M. Day, editors, Human Development across the Life Span: Educational and Psychological Applications, pp. 89-102, Praeger Publishers, Westport, CT, 1999.

10. B. Velthouse and Y. Kandogan. Ethics in Practice: What are Managers Really Doing?. Journal of Business Ethics, 70, 151-163, 2007.

11. B. Woodward and D. C. Davis. The Relationship Between Ethical Decision Making and Ethical Reasoning in Information Technology Students. Journal of Information Systems Education, 18(2): 50-61, 78, Summer 2007. 